trainee and supervisor. It is not sufficient just to have lunch or play golf with one's colleagues!

Child and Family Liaison Service

SEBASTIAN KRAEMER

The Whittington Hospital

London N19 5NF

\section{Returning home}

DeAr Sirs

Dr Araya's sad article (Psychiatric Bulletin, February $1993,17,109-110$ ) is a reminder of the obstacles faced by overseas doctors attempting to return home (Patel \& Araya, 1992). I have resisted the desire to return to India, since the regulations imposed by the Medical Council of India virtually ensure that I could never work in an academic setting. For example, a research proposal I had submitted to the Indian Council of Medical Research to study traditional healing and mental illness in primary care in India was rejected on the technical ground that my postgraduate qualifications were not recognised by them. Ironically, I received a three year grant from the Beit Trust to conduct a similar study in Zimbabwe.

Many institutions in the UK which "assist" doctors from the developing world by bringing them to the UK for "training" entertain a naive view that, regardless of exposure to material wealth and political stability in the UK, these doctors would voluntarily return to their homes. Many have no means to re-establish a career, lack of financial support and failure of academic bodies in their home countries to recognise the value of their experience in the UK being the main problems.

However the Royal Colleges and the WHO could establish a direct communication with policy making bodies in developing countries to discuss crossrecognition of postgraduate qualifications to facilitate transfer of health care personnel around the world. An international "doctors job bureau" to match individual doctors' needs with those of different clinical settings is long overdue, as is the establishment of research or resettlement funds for doctors returning to the developing world.

I disagree with Dr Araya on one point; I do not believe that legislative controls are useful. Doctors are individuals who have the right to search for and establish a lifestyle of their own. Many doctors from the Indian subcontinent would return home if the right opportunity arose. In place of coercion we need recognition of our difficulties and help to establish means to return home. The only other recourse would be to stay in the West, or return home to fulltime private medical practice.

Institute of Psychiatry

VikRAM PATEL

London SE5 8AF

\section{Reference}

Patel, V. \& Araya, R. (1992) Trained overseas, unable to return home: plight of doctors from developing countries. Lancet, 339, 110-111.

\section{Audit in the psychiatry of learning disabilities}

\section{DEAR SIRS}

We were interested in Carpenter \& Kanagaratnam's account of group audit in the South Western Region (Psychiatric Bulletin, February 1993, 17, 91-92). Given the complex needs of adults with learning disabilities (LD), regional audit with specialist peers is complementary to local audit activities with multidisciplinary teams and general psychiatry colleagues. Since 1990, our four-monthly Psychiatry of LD Sub-speciality Committee meetings have included a two hour audit session attended by all consultants and senior registrars in the South East Thames region.

Initially, case-notes were peer-reviewed using a specially designed audit questionnaire to compare the quality of note-keeping, clinical assessment and management practices. We record essential sociodemographic, historical, functioning and management data but have difficulties applying the ICD-9/10 and DSM-III-R diagnostic classification to clients' diverse mental health needs (MHN). Peerreview of previously audited case-notes assesses the implementation of clinical management plans and evidence for client and carer satisfaction.

Specific audit projects completed include a regional survey of depot neuroleptic usage, pilot survey of services for adults with $\mathrm{LD}$ and $\mathrm{MHN}$, and a district survey of GP satisfaction. Current projects include a regional survey on use of the Mental Health Act and district audit on the appropriateness of referrals. Our pilot survey revealed a lack of specific data on service-users and we are currently undertaking a regional survey of health and social care services for adults with LD and MHN.

We agree that establishing regional audit requires a well-attended and supportive peer-review group with individuals willing to coordinate audit projects. Our current audit cycle difficulties also concern agreeing and revising process standards for the assessment and care of specific client groups. Future hospital and community audit projects could include less welldefined client groups such as those with depression, schizophrenia, dementia or challenging behaviours. Audit should also demonstrate that our interventions maintain or improve the functioning and quality of life for clients with various MHN (Gravestock et al, 1991). Given that many clients have multiple chronic health and social care needs, 